\title{
PHARMACOKINETICS AND TISSUE DEPLETION OF DOXYCYCLINE ADMINISTERED AT HIGH DOSAGE TO BROILER CHICKENS VIA THE DRINKING WATER
}

\author{
Pai-Feng HSIAO ${ }^{1}$, Shao-Kuang CHANG ${ }^{2}$, Tien-Huan $\mathrm{Hsu}^{1}, \mathrm{Kuang}^{\mathrm{P}} \mathrm{PLI}^{1}$ \\ and Chi-Chung $\mathrm{CHOU}^{{ }^{*}}$ \\ ${ }^{1}$ Department of Veterinary Medicine, College of Veterinary Medicine, \\ National Chung Hsing University, No. 250, Kuo-Kuang Rd., Taichung 402, Taiwan; \\ ${ }^{2}$ Institute of Veterinary Medicine, School of Veterinary Medicine, \\ National Taiwan University, Taipei, Taiwan
}

(Received 27 February 2016; accepted 15 July 2016)

\begin{abstract}
The recommended use of doxycycline (DC) to broiler chicken is $100 \mathrm{mg} / \mathrm{L}$ via the drinking water and a 7-day withdrawal time (WDT). However, study of a higher dosage is desirable because of the possible increase of antimicrobial resistance and disease spectrum. Tissue DC residues exceeding the current maximum residue levels (MRL) was our major concern. Therefore, serum concentration and tissue depletion of DC hyclate after administration of $200 \mathrm{mg} / \mathrm{L}$ of DC in the drinking water for five consecutive days were studied. The steady-state DC concentration $(8.3 \pm 0.9 \mu \mathrm{g} / \mathrm{mL})$ was reached on the third day of medication. The elimination constant $(0.05 \pm 0.01 \mathrm{1} / \mathrm{h})$, half-life $(14.9 \pm 1.4 \mathrm{~h})$, area under concentration versus time curve $(81.0 \pm 9.9 \mathrm{~h} \cdot \mu \mathrm{g} / \mathrm{mL})$ and mean residence time $(22.7 \pm$ $2.5 \mathrm{~h}$ ) were obtained using a non-compartmental pharmacokinetic model. It was determined that the current 7-day WDT regulation was still legitimate for the kidney and liver as well as for the breast and leg muscles, which were estimated by linear regression analysis of the $99 \%$ upper distribution limit. The unregulated heart and gizzard were considered safe even when the lowest MRL of muscle $(100 \mathrm{ng} / \mathrm{g})$ was applied. While at the present time the extra-label use of drugs is only allowed under specific conditions, in the future it may become necessary to increase the general dosage of DC, and the current results suggest a safe range of DC hyclate in chicken; however, skin/fat tissue residues warrant further studies.
\end{abstract}

Key words: Doxycycline hyclate, pharmacokinetics, broiler, heart and gizzard, withdrawal time

Doxycycline (DC) hyclate is a semi-synthetic, second-generation tetracycline antibiotic that exerts its antimicrobial activity mainly by binding to the $30 \mathrm{~S}$ ribosomal subunit of bacteria to interfere with protein synthesis (Papich and Riviere, 2013; Nguyen et al., 2014). DC is 5 to 10 times more lipophilic, result-

*Corresponding author: ccchou@nchu.edu.tw; Phone: 00886 (4) 22840405177; Fax: 00886 (4) 22862073 
ing in higher bioavailability and tissue penetration, larger volume of distribution, and longer elimination period (Papich and Riviere, 2013). DC is primarily excreted into the faeces via non-biliary routes; hence, it is less toxic to patient with hepatic and renal insufficiency (Andrade and Tulkens, 2011; Plumb, 2015).

Despite the wide use in human medicine, DC has been contraindicated in pregnancy and in young animals due to its potential for disrupting bone and tooth development, and thus the food safety concern remains. In veterinary medicine, DC has been approved for use in broiler chickens via the drinking water $(100 \mathrm{mg} / \mathrm{L}$ or $20 \mathrm{mg} / \mathrm{kg}$ body weight) for 5 consecutive days, and a 7-day withdrawal time (WDT) is instigated. However, in the future it may become necessary to increase its dosage in poultry because of increasing antimicrobial resistance and disease spectra. Till now, in broiler chicken the pharmacokinetic information has been limited and mainly based on single daily dosing instead of continuous administration via the drinking water as practised under farm conditions.

The maximal residue limits (MRL) established by European Union for doxycycline in poultry are $100 \mathrm{ng} / \mathrm{g}$ for muscle, $300 \mathrm{ng} / \mathrm{g}$ for liver and skin, and $600 \mathrm{ng} / \mathrm{g}$ for kidney. Earlier residue data on broilers with oral medication of $20 \mathrm{mg} / \mathrm{kg}$ body weight (BW) daily for 4-5 days indicated that the DC levels in muscle, liver and kidney on the 5th day after the final medication were all below their MRLs (Anadón et al., 1994; El-Gendi et al., 2010). Recently, one report of DC given at a lower dose $(10 \mathrm{mg} / \mathrm{kg})$ for 5 consecutive days indicated that the DC residue on the 7th day after drug withdrawal was also safe (Gajda et al., 2014). Nevertheless, tissue residue levels in possible extra-label use (double concentration) have not been investigated. It is questionable whether or not the current WDT are appropriate under field conditions. In addition, the depletion of DC from the gizzard and heart was unknown, although these organs are popular edible parts in eastern countries; as a result, no reference WDT was available. The present study was the first pharmacokinetic assessment of DC hyclate in chicken medicated via the drinking water in line with the field practice.

\section{Materials and methods}

\section{Chemicals and reagents}

Doxycycline (as hyclate) powder was supplied by BIOVET (HydroDoxx ${ }^{\circledR}$ $500 \mathrm{mg} / \mathrm{g}$, Bulgaria). Analytical grade DC hyclate standard for high-performance liquid chromatography (HPLC) was purchased from Sigma Aldrich (St. Louis, $\mathrm{MO}$, USA), and the solid phase extraction (SPE) cartridges $(\mathrm{COOH}, 500 \mathrm{mg}$ in $3 \mathrm{~mL}$ syringe tube) were purchased from J. T. Baker (Center Valley, PA, USA). The acetonitrile (ACN), ethyl acetate (EA), methanol (MeOH) (Echo Chemical, Toufen, Taiwan), hydrochloric acid, sodium hydroxide, phosphoric acid (Union 
Chemical Works, Hsinchu, Taiwan), oxalic acid, and trichloroacetic acid (Panreac Applichem, Castellar del Vallés, Spain) were all analytical grade.

\section{Animals}

Thirty clinically healthy, 1-day-old conventional broiler chickens were raised in-house until the 16th day, at which time their average body weight reached $732 \pm$ $72 \mathrm{~g}$. The chickens were housed indoors under hygienic conditions and fed diets free of anticoccidials and antibiotics. The experimental protocols involving live animals were approved by the Institutional Animal Care and Use Committee of National Chung Hsing University, Taichung, Taiwan.

\section{Drug administration and sample collection}

Two hundred $\mathrm{mg} / \mathrm{L}$ of DC in drinking water was administered ad libitum to the chickens for five consecutive days. The daily intake of dose was estimated to be approximately $35-40 \mathrm{mg} / \mathrm{kg}$ (body weight) by calculating the total amount of medicated water ingested. The recorded daily intake of water volume was consistent for each cage $(1500-1700 \mathrm{~mL})$ and averaged $150-170 \mathrm{~mL} /$ day per chicken. For the serum pharmacokinetic study, $1.5-\mathrm{mL}$ blood samples were collected from the wing veins. Three broilers each were sampled at $6,12,24,48$, 72,96 and $120 \mathrm{~h}$ during the 5-day medication period and 6 broilers were sampled at $0,1,2,4,6,8,12,18$ and $24 \mathrm{~h}$ in the first 24-hour withdrawal period. Blood samples were settled for $2 \mathrm{~h}$ at $4{ }^{\circ} \mathrm{C}$ and centrifuged at $1,400 \mathrm{~g}$ for $10 \mathrm{~min}$ for serum collection. For the tissue depletion study, five broilers each were sacrificed with electrocution at the 3rd, 5th and 7th day after the last dose, and the heart, gizzard, breast muscle, leg muscle, liver and kidney were collected.

\section{Sample preparation and drug analysis}

Sample preparations and the HPLC method for DC determination were modified from previous reports (Gastearena et al., 1993; Gajda et al., 2008) and validated for this study. Briefly, for serum samples, $0.5 \mathrm{~mL}$ serum was mixed with $0.5 \mathrm{~mL}$ of phosphoric acid buffer $(0.2 \mathrm{M}, \mathrm{pH}$ 6) before $3 \mathrm{~mL}$ of ethyl acetate (EA) was added, and vortexed for $5 \mathrm{~min}$. The mixtures were centrifuged at $1,700 \mathrm{~g}$ for $10 \mathrm{~min}$ and $2.5-\mathrm{mL}$ supernatants were collected and evaporated to dryness in a chemical hood under gentle nitrogen stream. The sample was then reconstituted with $0.2 \mathrm{~mL}$ of mobile phase for HPLC analysis. For tissue samples, $5 \mathrm{~g}$ of minced tissue was vortexed in $3 \mathrm{~mL}$ of oxalic acid buffer $(0.02 \mathrm{M}, \mathrm{pH} 4)$ for $30 \mathrm{sec}$. The mixture was extracted with $15 \mathrm{~mL}$ of EA and $0.5 \mathrm{~mL}$ of $10 \%$ trichloroacetic acid. This liquid-liquid extraction was repeated twice with EA alone, and the total supernatants were pooled for SPE. The SPE cartridge was first conditioned with $5 \mathrm{~mL}$ of EA before loading the supernatant. After washing with $2 \mathrm{~mL}$ of EA, the analyte was eluted with $2 \mathrm{~mL}$ of mobile phase, and $50 \mu \mathrm{L}$ 
was used for HPLC analysis. The HPLC system consisted of a pump (1525 binary pump, Waters), an injector (model 7725i, Rheodyne), and an ultraviolet detector (2489 UV/Visible, Waters). A reverse-phase column (Luna ${ }^{\circledR} \mathrm{C} 8,5 \mu \mathrm{m}$ particle size, $250 \times 4.6 \mathrm{~mm}$, Phenomenex) was used for chromatographic separation at ambient temperature with a mobile phase consisting of $20 \mathrm{mM}$ oxalic acidACN-MeOH (65:20:15) set at a flow rate of $1 \mathrm{~mL} / \mathrm{min}$. Ultraviolet detection was performed at $355 \mathrm{~nm}$. The recoveries at levels equivalent to 0.5, 1 and 1.5 MRLs for respective tissues were evaluated and the limits of detection and quantification were $5 \mathrm{ng} / \mathrm{g}$ and $16 \mathrm{ng} / \mathrm{g}$, respectively.

\section{Pharmacokinetics}

Serum pharmacokinetic parameters were analysed using commercially available software (WinNonlin ${ }^{\circledR}$ version 1.1, Pharsight) utilizing non-compartmental analysis. The area under the concentration-time curve (AUC), the area under the first moment curve (AUMC), the elimination constant $\left(\mathrm{K}_{\mathrm{e}}\right)$, the elimination half-life $\left(\mathrm{T}_{1 / 2}\right)$ and the mean residence time (MRT) were obtained accordingly. The DC concentrations, AUC, AUMC, $\mathrm{K}_{e}, \mathrm{~T}_{1 / 2}$ and MRT were shown as mean \pm SEM. Clearance (CL) and steady-state volume of distribution (Vss) can be calculated using the following formula: $\mathrm{CL}=$ Dose $/ \mathrm{AUC}$, and Vss $=\mathrm{MRT} \times \mathrm{CL}$.

\section{Results}

\section{Pharmacokinetic study}

The serum DC concentration rose to $4.4 \pm 0.4 \mu \mathrm{g} / \mathrm{mL}$ at the 6 th $\mathrm{h}$ after the first medication and reached a steady-state concentration of $8.3 \pm 0.9 \mu \mathrm{g} / \mathrm{mL}$ at $72 \mathrm{~h}$ (Fig. 1a). After the last dose, the DC level declined to half of the steady-state concentration after $6 \mathrm{~h}$. The average serum concentration at the 24th $\mathrm{h}$ was around $2.0 \pm 0.3 \mu \mathrm{g} / \mathrm{mL}$ (Fig. 1b). The concentration-time curve during the first 24-h elimination was best described by a non-compartmental pharmacokinetic model, of which the variables were listed and compared to previous studies (Table 1).

\section{Tissue residues}

On the 3rd day, in decreasing order, the DC concentration was the highest in the heart, followed by the gizzard, kidneys, liver, leg muscle and breast muscle. The heart and the breast muscle contained $252 \pm 93 \mathrm{ng} / \mathrm{g}$ and $62 \pm 16 \mathrm{ng} / \mathrm{g}$ of DC, respectively. On the 5th day, the tissue DC concentrations all decreased below their respective MRLs (Fig. 2). A differential depletion rate of tissue residues during the first 7 days was also noted (Table 2). The drug concentration fell more precipitately on days $5-7$ than on days $3-5$ for breast muscle, liver and kidney. 
(a)



(b)

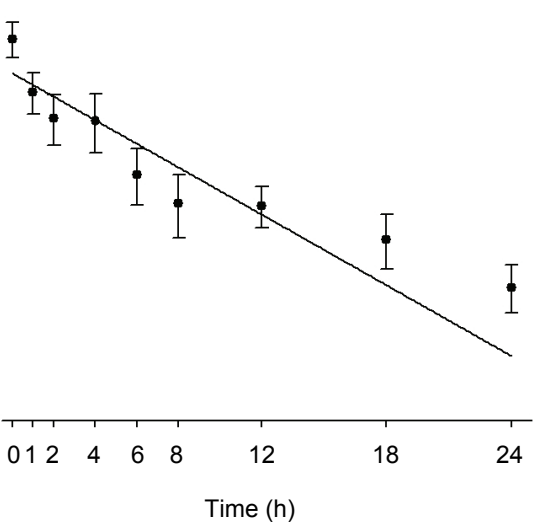

Fig. 1. Mean serum doxycycline (DC) concentration during (a) 5-day medication period at $40 \mathrm{mg} / \mathrm{kg} \mathrm{BW}$ via drinking water, and (b) the first 24 hours after the last dosage administered (mean \pm SEM, $\mathrm{n}=6$ )

\section{Table 1}

Pharmacokinetic parameters of doxycycline (DC) after medication via the drinking water for 5 days (comparison was made to previous studies after single oral dose)

\begin{tabular}{lcccc}
\hline Variables & Present study & $\begin{array}{c}\text { Soliman et al. } \\
(2015)\end{array}$ & $\begin{array}{c}\text { El-Gendi et al. } \\
(2010)\end{array}$ & $\begin{array}{c}\text { Hantash et al. } \\
(2008)\end{array}$ \\
\hline Breed & Cobb & - & Hubbard & - \\
Drug salt & hyclate & $\mathrm{HCl}$ & $\mathrm{HCl}$ & $\mathrm{HCl}$ \\
Route & Drinking water & Intra-crop & Intra-crop & Intra-crop \\
Dose & 40 & 20 & 20 & 20 \\
Duration & 5 days & Single dose & Single dose & Single dose \\
$\mathrm{C}_{\text {max }}(\mu \mathrm{g} / \mathrm{mL})$ & - & $4.7 \pm 0.6$ & $4.5 \pm 0.2$ & $5.4 \pm 0.3$ \\
$\mathrm{C}_{\mathrm{ss}}(\mu \mathrm{g} / \mathrm{mL})$ & $8.3 \pm 0.9$ & - & - & - \\
$\mathrm{K}_{\mathrm{e}}\left(\mathrm{h}^{-1}\right)$ & $0.05 \pm 0.01$ & $0.05 \pm 0.002$ & $0.12 \pm 0.01$ & $0.04 \pm 0.01$ \\
$\mathrm{~T}_{1 / 2}(\mathrm{~h})$ & $14.9 \pm 1.4$ & $13.9 \pm 0.4$ & $5.7 \pm 0.3$ & $13.9 \pm 0.8$ \\
$\mathrm{MRT}(\mathrm{h})_{\mathrm{AUC}(\mu \mathrm{g} \cdot \mathrm{h} / \mathrm{mL})}$ & $22.7 \pm 2.5$ & - & - & $9.4 \pm 0.2$ \\
$\mathrm{AUMC}\left(\mu \mathrm{g} \cdot \mathrm{h}^{2} / \mathrm{mL}\right)$ & $2975.4 \pm 484.7$ & $21.7 \pm 1.48$ & $39.8 \pm 4.3$ & $89.4 \pm 3.0$ \\
& & - & - & $836.7 \pm 19.7$ \\
\hline
\end{tabular}

For the estimation of WDT in these tissues, 99\% upper distribution limits of the $3 \mathrm{rd}$, 5th and 7th days were used to establish the regression line. The time at which the regression lines intercepted with the MRL was the estimated WDT. The results suggested that the kidney, the liver and the two muscles all fell within the current WDT regulation of 7 days (Fig. 3). The gizzard and the heart were also evaluated using the current MRLs established for kidney, liver and muscle (Fig. 4). 




Fig. 2. Depletion profile of doxycycline (DC) in various tissues (mean \pm SEM, $n=5$ )

Table 2

Comparison on the rate of doxycycline (DC) depletion (by percentage decrease) between two sampling time points

\begin{tabular}{lcccccc}
\hline Tissue & Gizzard \% & Heart \% & Breast \% & Leg $\%$ & Liver \% & Kidney \% \\
\hline Days 3-5 & 60 & 69 & 38 & 35 & 49 & 9 \\
Days 5-7 & 60 & 35 & 51 & 17 & 81 & 68 \\
\hline
\end{tabular}

\section{Discussion}

Doxycycline has been used for the treatment of avian respiratory infectious diseases such as chlamydiosis, mycoplasmosis and other aerobic/anaerobic bacterial infections, but its serum pharmacokinetic data under double-concentration use and field conditions were unavailable in previous studies. In the present study, the $\mathrm{C}_{\mathrm{ss}}(8.3 \pm 0.9 \mu \mathrm{g} / \mathrm{mL})$ was above most inhibitory concentrations required for DC to exert a bacteriostatic effect against Staphylococcus aureus $(4.8 \mu \mathrm{g} / \mathrm{mL})$, Streptococcus pneumoniae $(1.6 \mu \mathrm{g} / \mathrm{mL})$, Pasteurella multocida $(1.6 \mu \mathrm{g} / \mathrm{mL})$, and Escherichia coli $(8 \mu \mathrm{g} / \mathrm{mL})$ (Cunha et al., 2000). This $\mathrm{C}_{\mathrm{ss}}$ was also 42 times higher than the $\mathrm{MIC}_{90}$ for Mycoplasma gallisepticum $(0.125 \mu \mathrm{g} / \mathrm{mL})$ (Burch and Valks, 2002). After drug withdrawal, the concentration-time curve during the first 24-h elimination was compared to previous studies (Hantash et al., 2008; Soliman et al., 2015) (Table 1). While most parameters showed an expected increase likely associated with the increased dosages, the $T_{1 / 2}$ was mostly comparable to pub- 
lished reports despite differences in the dosing regimen. The results may suggest the proper capacity of chicken to eliminate DC under current extra-label drug use (ELDU) conditions.
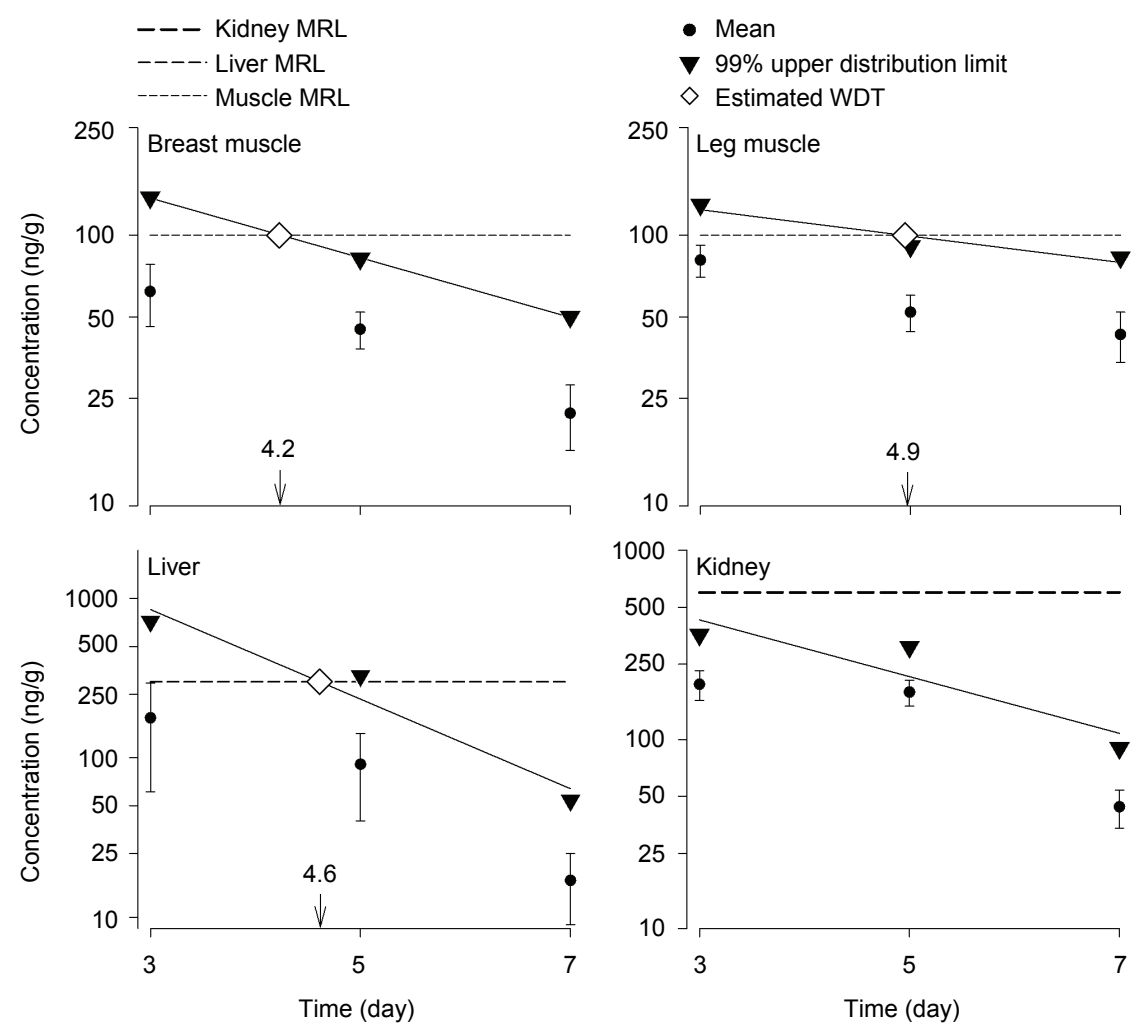

Fig. 3. Estimation of withdrawal time (WDT) on muscles, liver, and kidney by linear regression of the $99 \%$ upper distribution limits (mean \pm SEM, $n=5$ )

At the usual recommended dose $(20 \mathrm{mg} / \mathrm{kg} \mathrm{BW})$ of DC, the residues should fall below their MRLs in the respective tissues within the regulated 7 days (the WDT). The present investigation revealed that even at nearly double dosage (35$40 \mathrm{mg} / \mathrm{kg} \mathrm{BW}$ ), the residues in kidney, liver and muscles all decreased below their respective MRLs already 5 days after drug withdrawal, in the same way as in the case of the $20 \mathrm{mg} / \mathrm{kg} \mathrm{BW}$ dosage regimen (Anadón et al., 1994; El-Gendi et al., 2010). Probably, the current regulation actually allows certain degrees of safe caution. So far, MRLs have been established in four major edible tissues including kidney (600 ng/g), liver and skin (300 ng/g), and muscle (100 ng/g). The heart and gizzard, although being popular food items in many regions of the world, did not have recommended MRLs which could be used for estimating a proper WDT. Traditionally, WDT was established either by a non-parametric 
approach or by linear regression. The non-parametric approach has the disadvantage of no assumption from the obtained population data (Vranic et al., 2003) and the ethical concern of increased experimental animal number. On the other hand, the linear regression method depicting 99\% upper distribution limit was recommended by the Food and Drug Administration (Damte et al., 2012). With this method, the estimated WDT for gizzard and heart were both within 7 days based on the lowest MRL for muscle (100 ng/g) (Fig. 4). Therefore, while there were no recommended MRLs for these two tissues, our data suggested that the current 7-day WDT was likely enough to avoid residue infringement. In fact, the MRL determination for an organ/tissue also considers the theoretical standard food basket (consisting of $300 \mathrm{~g}$ muscle, $100 \mathrm{~g}$ liver, $50 \mathrm{~g}$ kidney, $50 \mathrm{~g}$ fat, $1500 \mathrm{~g}$ milk, $100 \mathrm{~g}$ eggs and $20 \mathrm{~g}$ honey) (WHO, 2009), which may differ in various cultures and countries. Since the gizzard and the heart were often considered as viscera in eastern cultures, their MRLs could be tentatively estimated based on the MRL of liver $(300 \mathrm{ng} / \mathrm{g})$. Under this assumption, a 5-day WDT for both heart and gizzard could be determined (Fig. 4). Extended from the food basket concept, the knowledge of total tissue residues also carries important implications regarding food safety. For instance, the chicken essence, which is the brewed juice of a whole gutted chicken body, might contain non-negligible amounts of DC if the WDT is not strictly followed. Estimation based on the current data indicated that an aliquot of chicken essence may contain at least $21 \mu \mathrm{g}$ of DC residues (assuming a $1.2-\mathrm{kg}$ chicken, $60 \%$ of which is muscle), which represents $12 \%$ of the acceptable daily intake (ADI) for this drug in a $60-\mathrm{kg}$ person. The number could increase to $32-64 \%$ of ADI if the skin were also included in the preparation of chicken essence (assuming the skin representing 10\% of the gutted torso and DC at MRL level). The current study provides reliable information for risk assessment of this drug under various food-basket assumptions because it is conducted in line with the manner the drug is administered in the field.

Some minor observations in this study are worth mentioning. The rank order of residue levels was the same as in previous studies using doxycycline $\mathrm{HCl}$ at $20 \mathrm{mg} / \mathrm{kg}$ BW (Anadón et al., 1994; El-Gendi et al., 2010), suggesting that the distribution and elimination behaviour of these two common DC salts might be similar. In this study, the breast and leg muscles were separately studied and found to exhibit one-day difference in WDT (4 days $v s$. 5 days). Differential distribution and elimination of antibiotics between these two muscle sites has been reported previously in pigeon (Yeh et al., 2008). A potential explanation might be the difference between the two sites in local blood flow, local capillary density and capillary permeability. While the basis for the differences between the two muscle sites is unknown, our results highlighted the fact that even very similar tissues might have different residual times. In addition, it is interesting to note that the DC concentration in the breast muscle, liver and kidney decreased more precipitately (by percentile) between days 5-7 than between days 3-5, while in 
the heart and leg muscle the DC concentration decreased more rapidly between days 3-5, indicating the differential rate of DC elimination by tissues. This difference was especially evident for the kidney ( $9 \% v s .68 \%)$. The reasons for the time-dependent differences in elimination and its influence on the WDT remain to be elucidated, but based on the fact that this phenomenon was also observed when DC was co-administered with the anticoccidial diclazuril in the feed $(1 \mathrm{mg} / \mathrm{kg})$ (El-Gendi et al., 2010), it is plausible that the relatively high plasma protein binding (80-90\%) (Papich and Riviere, 2013) and the varying degrees of tissue bindings of DC contributed to this observation.

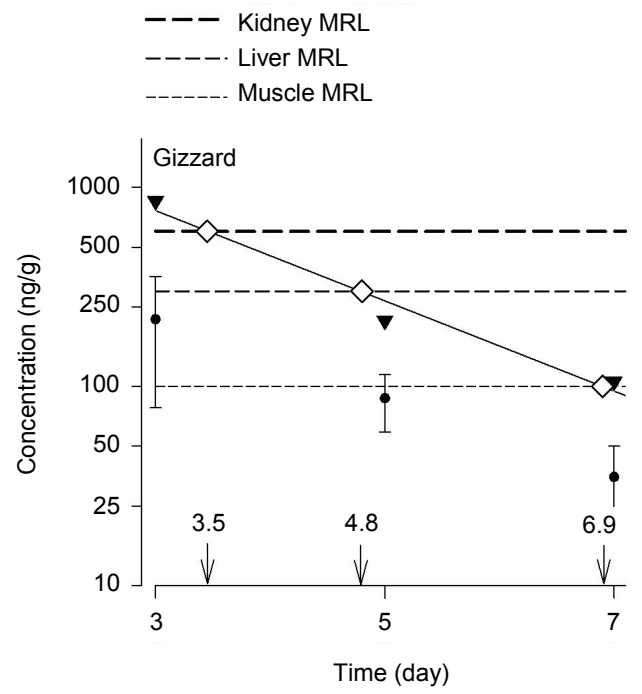

- Mean

- 99\% upper distribution limit

$\diamond$ Estimated WDT

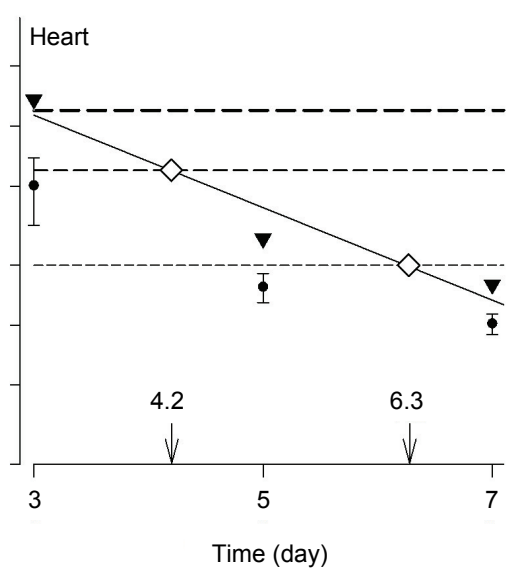

Fig. 4. Estimation of withdrawal time (WDT) on gizzard and heart based on various maximum residue levels (MRLs; mean \pm SEM, $\mathrm{n}=5$ )

In conclusion, the pharmacokinetic behaviour of DC administered at $40 \mathrm{mg} / \mathrm{kg}$ dosage level (200 mg/L water) was for the most part similar to that observed with the single dose $(20 \mathrm{mg} / \mathrm{kg})$ widely used in previous studies. All tissue residues were below their respective MRLs at times shorter than the regulated WDT. In addition to the common edible tissues (kidney, liver and muscles), the heart and the gizzard were also considered safe under the 7-day WDT regulation based on the most strict provisional MRL used for muscle. The current study also demonstrated a differential rate of DC depletion in the first and second half of the 7-day withdrawal period and documented differences in residual levels between breast and leg muscles. Although these results pointed to the conclusion that the current 7-day WDT might still be appropriate at the doubled dosage $(40 \mathrm{mg} / \mathrm{kg})$ level, it must be emphasised that our data are initial assessments, ELDU is not advisable, and the residue levels in skin/fat warrant further investigation. 


\section{References}

Anadón, A., Martinez-Larranaga, M. R., Diaz, M. J., Bringas, P., Fernandez, M. C., FernandezCruz, M. L., Iturbe, J. and Martinez, M. A. (1994): Pharmacokinetics of doxycycline in broiler chickens. Avian Pathol. 23, 79-90.

Andrade, R. J. and Tulkens, P. M. (2011): Hepatic safety of antibiotics used in primary care. J. Antimicrob. Chemother. 66, 1431-1446.

Burch, D. G. S. and Valks, M. (2002): Comparison of minimal inhibitory concentrations (MIC) against chicken mycoplasma of tiamulin and other antimicrobials and their concentrations in the blood. Proceedings of the 12th International Congress of the World Veterinary Poultry Association, Cairo, Egypt, p. 322.

Cunha, B. A., Domenico, P. and Cunha, C. B. (2000): Pharmacodynamics of doxycycline. Clin. Microbiol. Infect. 6, 270-273.

Damte, D., Jeong, H. J., Lee, S. J., Cho, B. H., Kim, J. C. and Park, S. C. (2012): Evaluation of linear regression statistical approaches for withdrawal time estimation of veterinary drugs. Food Chem. Toxicol. 50, 773-778.

El-Gendi, A. Y. I., Atef, M., Amer, A. M. M. and Kamel, G. M. (2010): Pharmacokinetic and tissue distribution of doxycycline in broiler chickens pretreated with either: Diclazuril or halofuginone. Food Chem. Toxicol. 48, 3209-3214.

Gajda, A., Posyniak, A. and Pietruszka, K. (2008): Analytical procedure for the determination of doxycycline residues in animals tissues by liquid chromatography. Bull. Vet. Inst. Pulawy 52, 417-420.

Gajda, A., Posyniak, A. and Tomczyk, G. (2014): LC-MS/MS analysis of doxycycline residues in chicken tissues after oral administration. Bull. Vet. Inst. Pulawy 58, 573-579.

Gastearena, I., Dios-Vièitez, M. C., Goñi, M. M., Renedo, M. J. and Fos, D. (1993): Determination of doxycycline in small serum samples by liquid chromatography. Application to pharmacokinetical studies on small laboratory animals. Chromatographia 35, 524-526.

Hantash, T. M., Abu-Basha, E. A., Roussan, D. A. and Abudabos, A. M. (2008): Pharmacokinetics and bioequivalence of doxycycline (Providox ${ }^{\circledR}$ and Doxyvet 0-50 $\mathrm{S}^{\circledR}$ ) oral powder formulations in chickens. Int. J. Poult. Sci. 7, 161-164.

Nguyen, F., Starosta, A. L., Arenz, S., Sohmen, D., Dönhöfer, A. and Wilson, D. N. (2014): Tetracycline antibiotics and resistance mechanisms. Biol. Chem. 395, 559-575.

Papich, M. G. and Riviere, J. E. (2013): Tetracycline antibiotics. In: Riviere, J. E. and Papich, M. G. (eds) Veterinary Pharmacology and Therapeutics. Wiley-Blackwell, USA. pp. 895-913.

Plumb, D. C. (2015): Doxycycline. In: Veterinary Drug Handbook. PharmaVet Inc., USA. pp. $365-370$.

Soliman, A. M., Aboubakr, M. and El-Hewaity, M. (2015): Bioequivalence study of two oral doxycycline formulations $\left(\right.$ Doxysol $^{\mathbb{B}}$ and Doxymed $^{\mathbb{B}}$ ) in healthy broiler chickens. Pharmacol. Pharm. 6, 1-8.

Vranic, M. L., Marangunich, L., Fernández Courel, H. and Fernández Suárez, A. (2003): Estimation the withdrawal period for veterinary drugs used in food producing animals. Anal. Chim. Acta 483, 251-257.

WHO (2009): JECFA assessment processes for residues of veterinary drugs. In: Sheffer, M. (ed.) Maximum Residue Limits for Pesticides and Veterinary Drugs. Word Health Organization, Geneva, Switzerland. pp. 7-14.

Yeh, L. C., Lee, W. M., Koh, B. W., Chan, J. P., Liu, C. H., Kao, J. P. and Chou, C. C. (2008): Development of amoxicillin enzyme-linked immunosorbent assay and measurements of tissue amoxicillin concentrations in a pigeon microdialysis model. Poult. Sci. 87, 577-587. 